\title{
A machine learning calibration model using random forests to improve sensor performance for lower-cost air quality monitoring
}

Naomi Zimmerman et al.

Correspondence to: R. Subramanian (subu@cmu.edu)

The copyright of individual parts of the supplement might differ from the CC BY 4.0 License. 

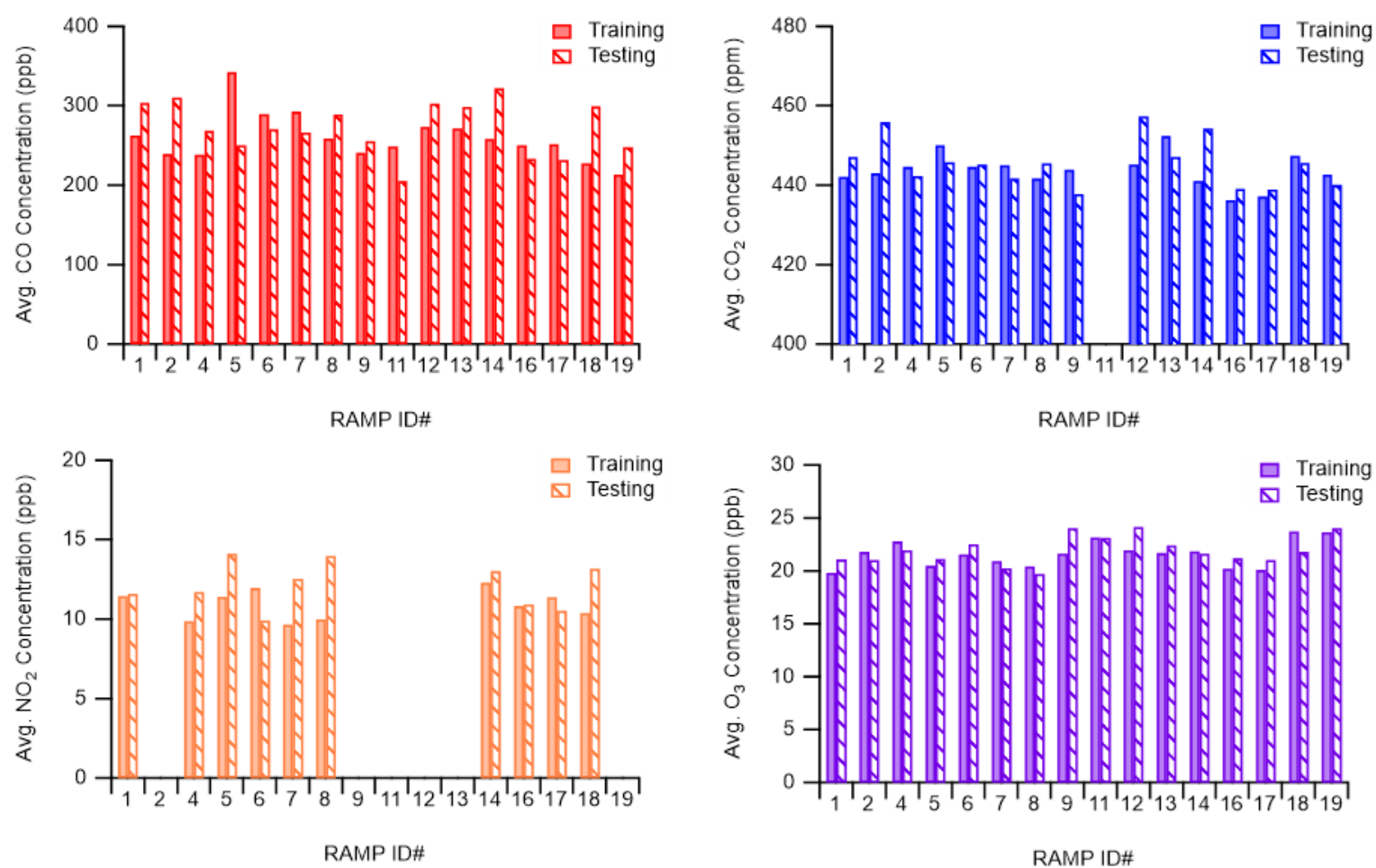

Figure S1. Average reference monitor concentrations during training and testing windows for each RAMP 

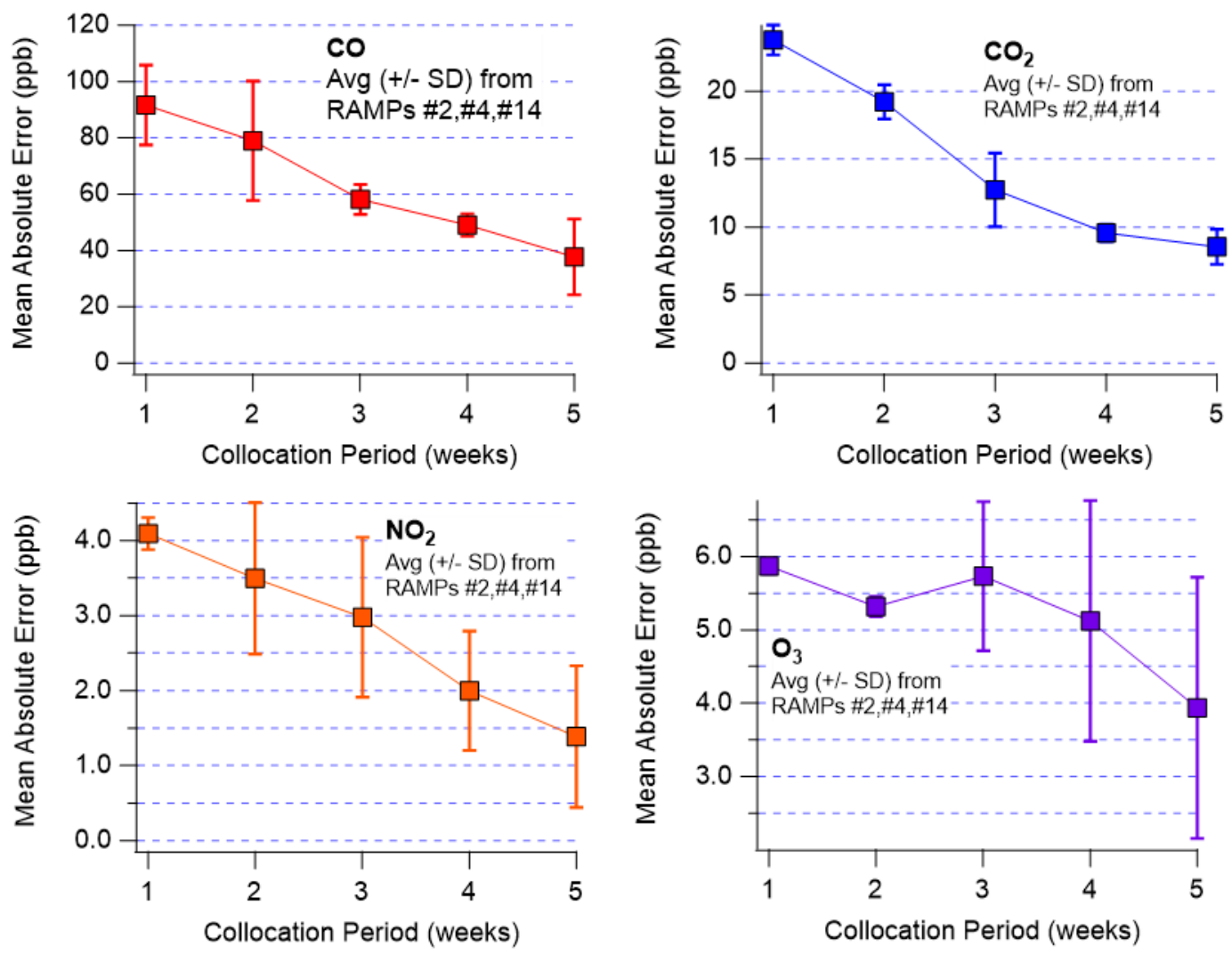

Figure S2: Choosing collocation length for training. Optimization assessed on a subset of three RAMPs (RAMP \#2, \#4, and \#14). Ultimately a 4-week collocation period was chosen as being the best across all four species.

Table S1: Change in model performance if one consecutive 4-week colocation at the beginning of the study is conducted vs spacing out training data throughout the study in 8 half week increments.

Impact of using one consecutive four week training window vs. distributed half week colocations

\begin{tabular}{|c|c|c|c|c|}
\hline Metric & CO & $\mathrm{CO}_{2}$ & $\mathrm{NO}_{2}$ & $\mathbf{O}_{3}$ \\
\hline RMSE & +11.9 ppb & +3.2 ppm & $+0.4 \mathrm{ppb}$ & $+1.6 \mathrm{ppb}$ \\
\hline MAE & $+12.1 \mathrm{ppb}$ & +1.8 ppm & $+0.4 \mathrm{ppb}$ & $+1.6 \mathrm{ppb}$ \\
\hline Pearson $r$ & -0.01 & -0.03 & -0.08 & -0.05 \\
\hline
\end{tabular}


Table S2. Metrics used for comparing sensor data. $M$ indicates a value measured by one of the sensors participating in the experiment and $\mathrm{O}$ indicates the observations from the reference measurements.

\begin{tabular}{|c|c|c|c|}
\hline Statistic & Abbrev. & Formula & Characteristics \\
\hline $\begin{array}{l}\text { Mean Bias } \\
\text { Error }\end{array}$ & MBE & $\mathrm{MBE}=\overline{\mathrm{M}}-\overline{\mathrm{O}}$ & $\begin{array}{l}\text { Estimation of the magnitude of differences (bias) } \\
\text { between sensors estimation and reference values } \\
\text { averaged over the whole sampling period }\end{array}$ \\
\hline $\begin{array}{l}\text { Mean } \\
\text { Absolute } \\
\text { Error }\end{array}$ & MAE & $\mathrm{MAE}=\frac{1}{\mathrm{n}} \sum_{i=1}^{n}\left|M_{i}-O_{i}\right|$ & $\begin{array}{l}\text { - Indicates the average of the magnitude of the errors. } \\
\text { - Sensitive to outliers. }\end{array}$ \\
\hline $\begin{array}{l}\text { Pearson } \\
\text { Correlation } \\
\text { Coefficient }\end{array}$ & $\mathrm{r}$ & $\mathrm{r}=\frac{\sum_{i=1}^{n}\left(M_{i}-\bar{M}\right)\left(O_{i}-\bar{O}\right)}{\sqrt{\sum_{i=1}^{n}\left(M_{i}-\bar{M}\right)^{2}\left(O_{i}-\bar{O}\right)^{2}}}$ & $\begin{array}{l}\text { Measures the strength and the direction of a linear } \\
\text { relationship between two variables. }\end{array}$ \\
\hline $\begin{array}{l}\text { Root Mean } \\
\text { Square Error }\end{array}$ & RMSE & $R M S E=\sqrt{\frac{1}{n}} \sum_{i=1}^{n}\left(M_{i}-O_{i}\right)^{2}$ & $\begin{array}{l}\text { - Magnitude of the error and retains the variable's unit } \\
\text { - Sensitive to extreme values and to outliers }\end{array}$ \\
\hline $\begin{array}{l}\text { Centred Root } \\
\text { Mean Square } \\
\text { Error }\end{array}$ & CRMSE & $C R M S E=\sqrt{R M S E^{2}-M B E^{2}}$ & $\begin{array}{l}\text { - RMSE corrected for bias } \\
\text { - Measure of random error }\end{array}$ \\
\hline
\end{tabular}


Plots of Goodness of Fit (Results from Training, Figures S3-S6)
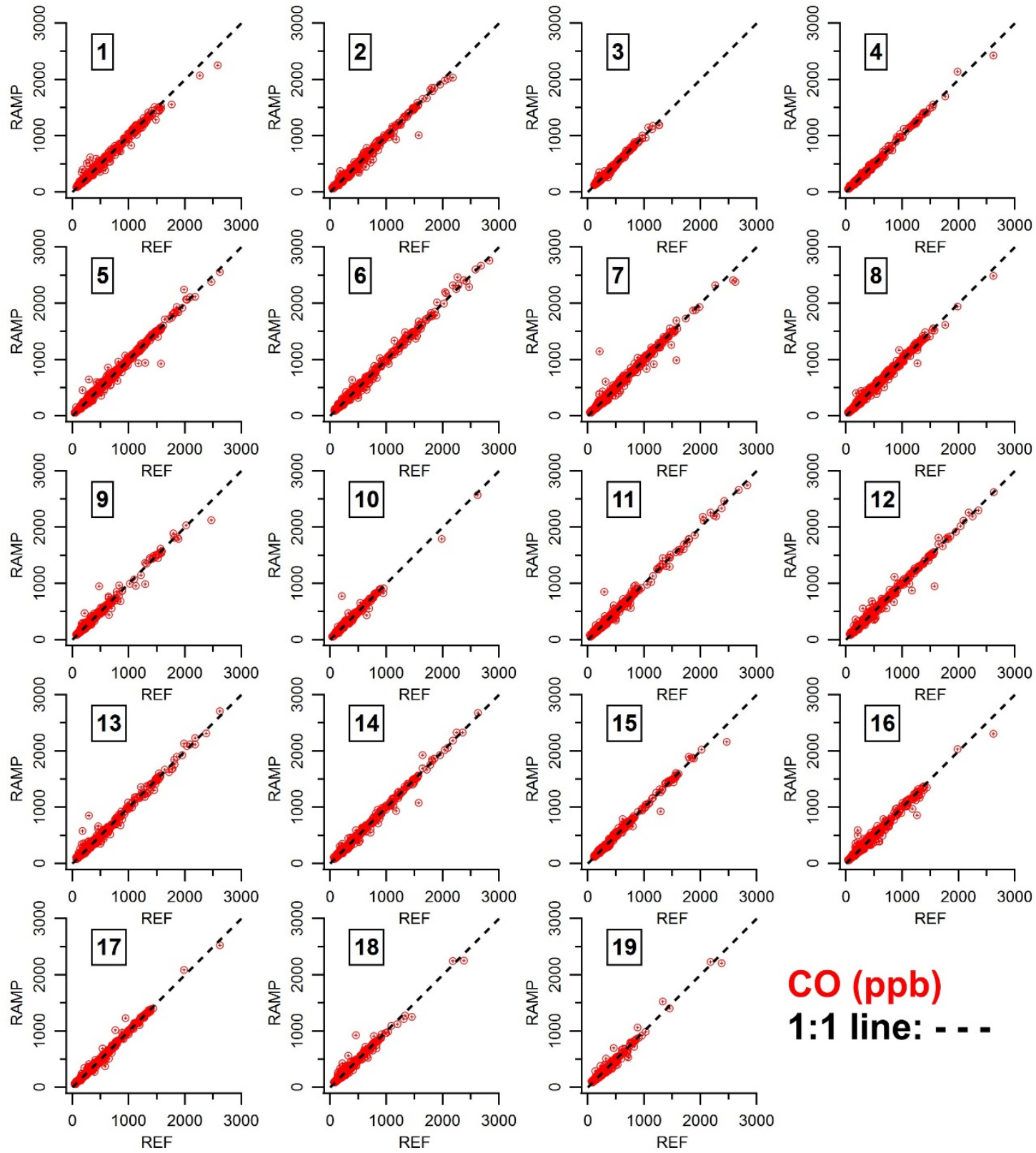

Figure S3: Goodness of fit on training data across all 19 RAMPs for $\mathrm{CO}$ using random forests. 

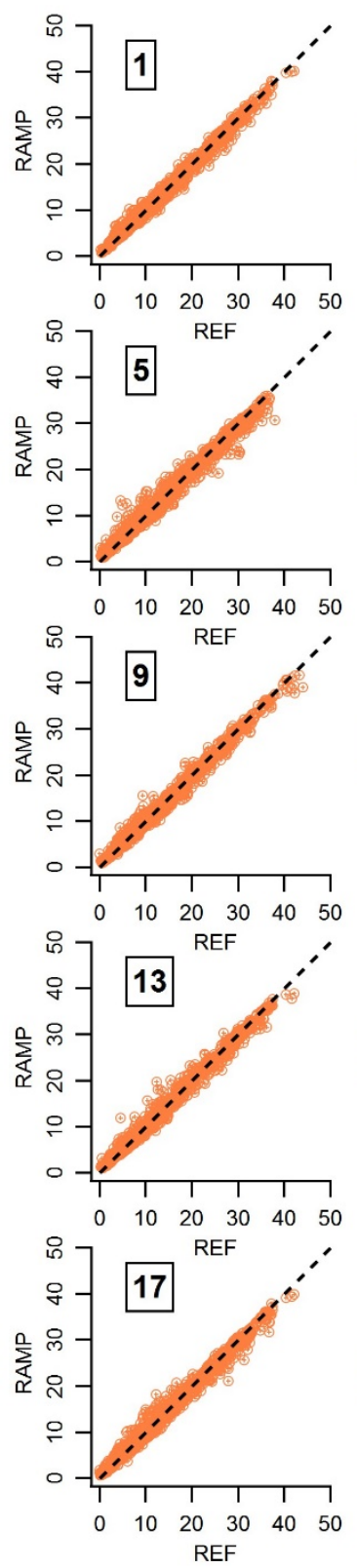
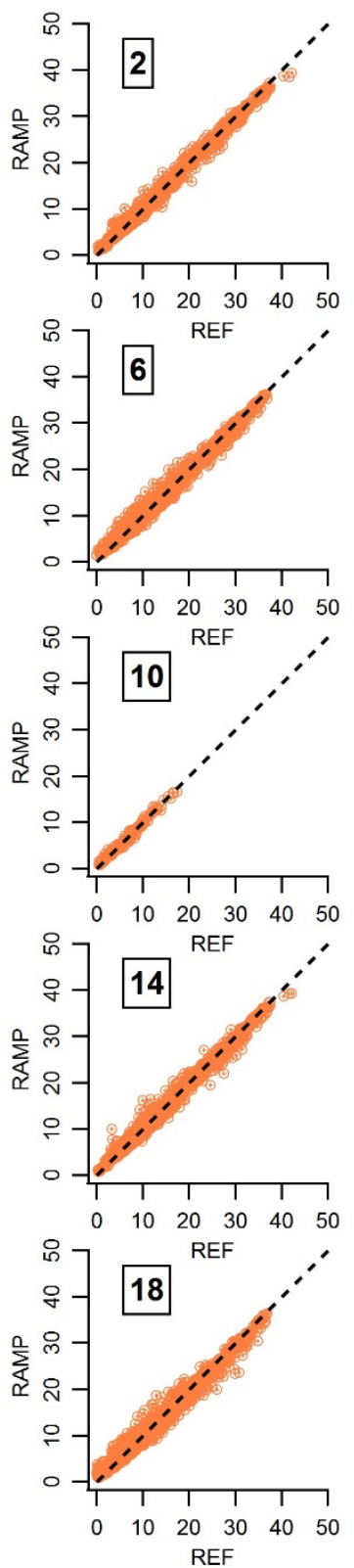
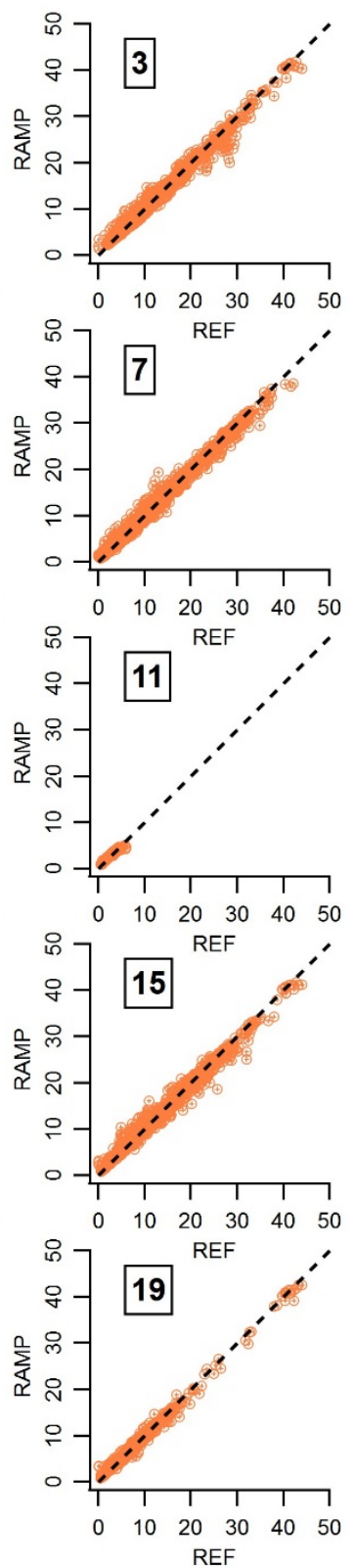
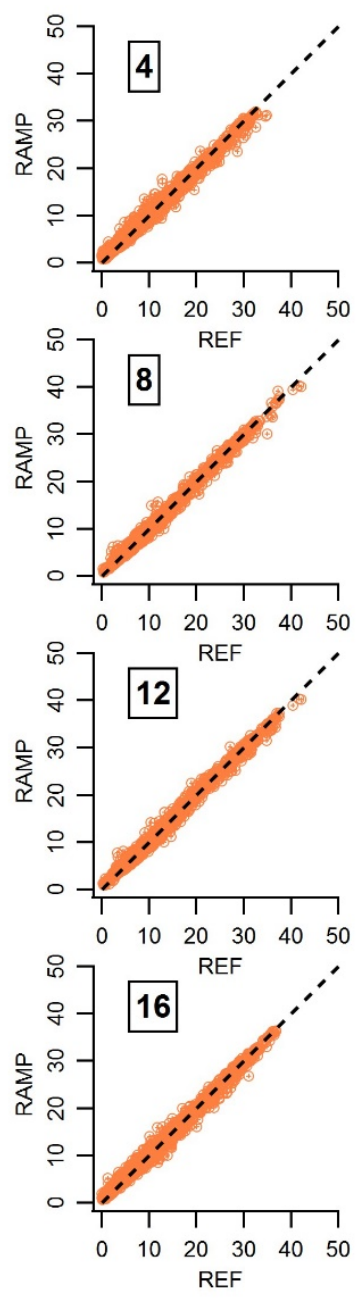

$\mathrm{NO}_{2}$ (ppb)

1:1 line: - -

Figure S4: Goodness of fit on training data across all 16 RAMPs for $\mathrm{NO}_{2}$ using random forests. 

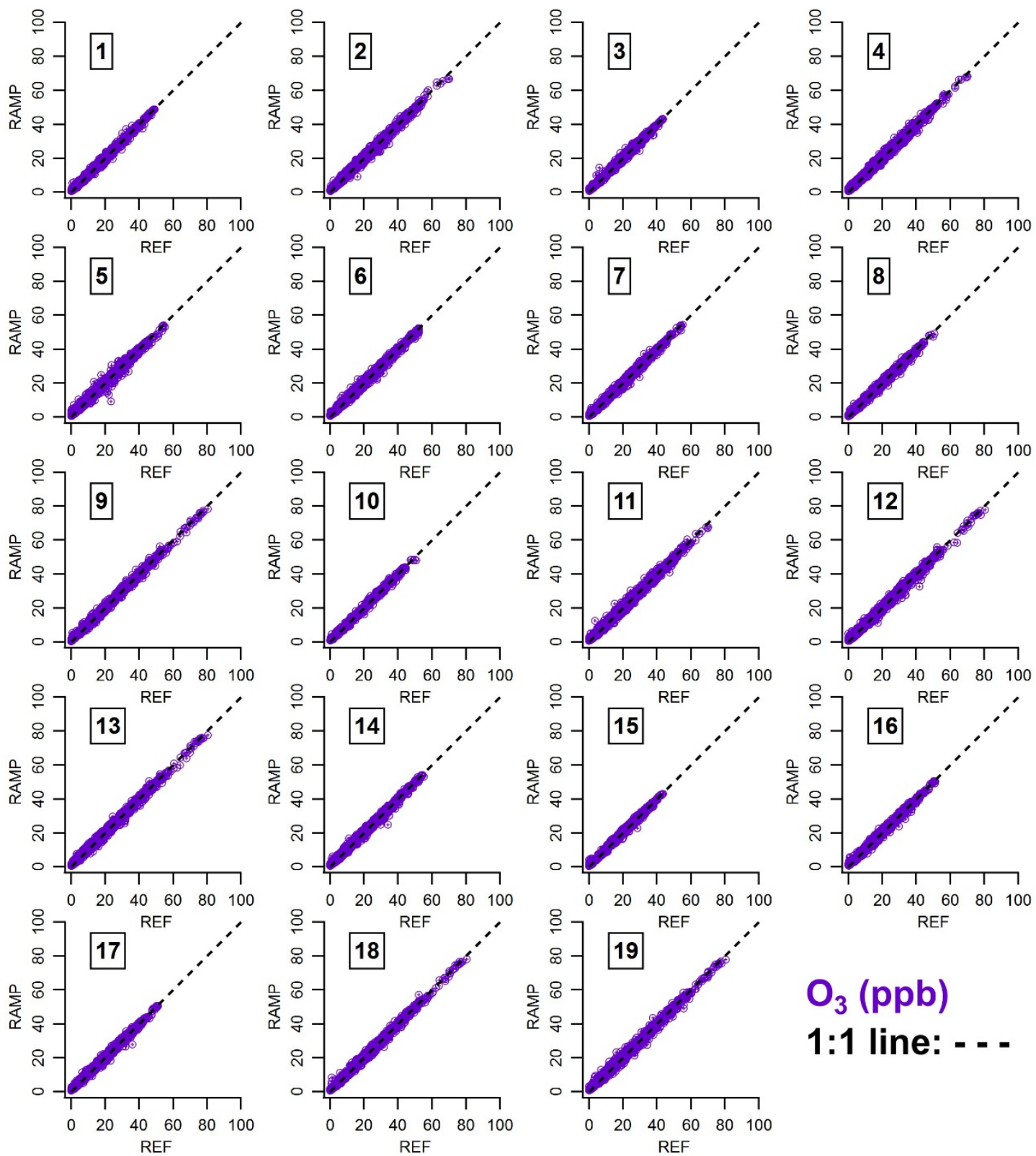

\section{$\mathrm{O}_{3}(\mathrm{ppb})$}

\section{1:1 line: - - -}

Figure S5: Goodness of fit on training data across all 19 RAMPs for $\mathrm{O}_{3}$ using random forests. 

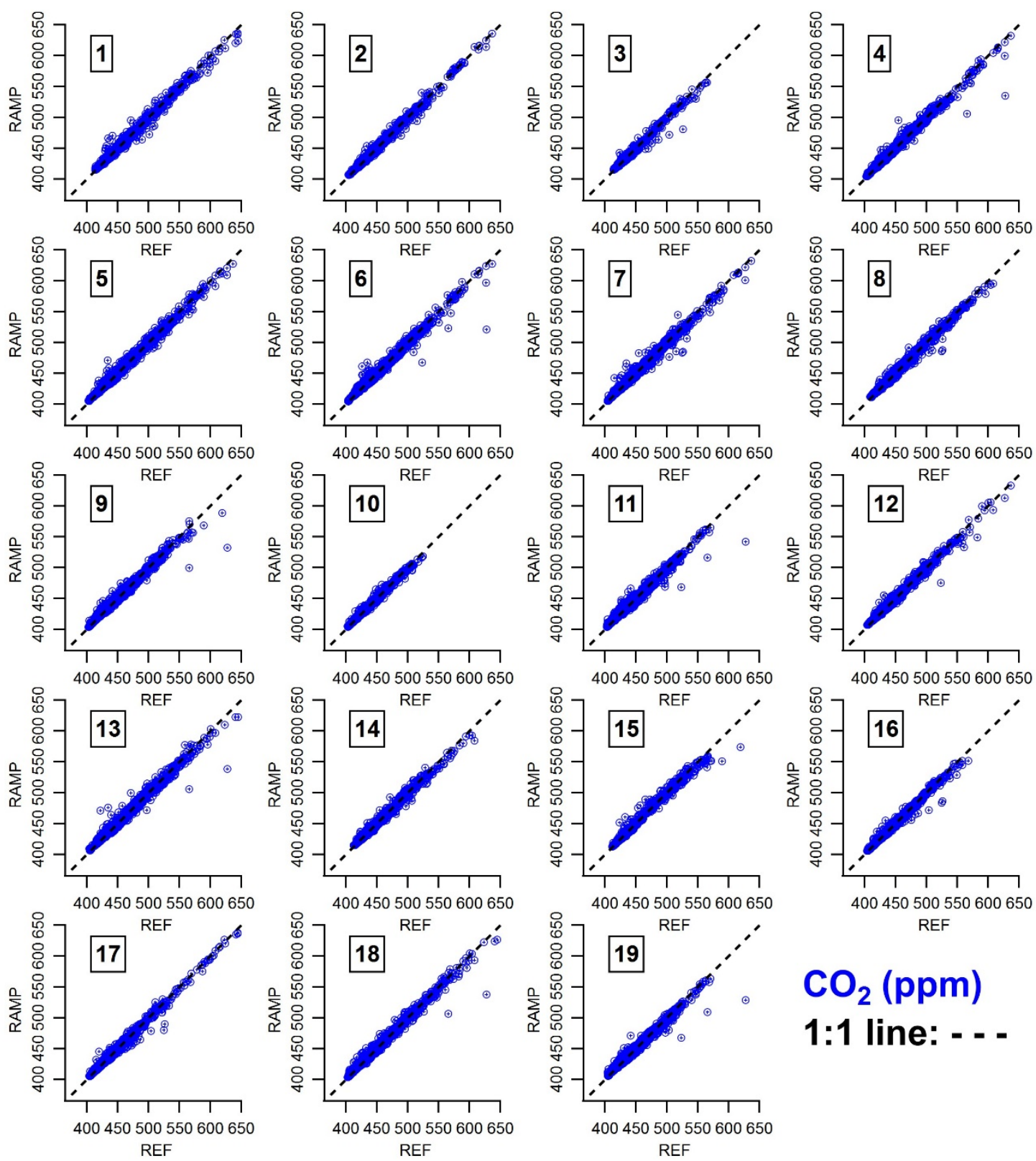

\section{$\mathrm{CO}_{2}(\mathrm{ppm})$}

\section{1:1 line: - - -}

Figure S6: Goodness of fit on training data across all 19 RAMPs for $\mathrm{CO}_{2}$ using random forests. 
Plots of Random Forest Performance by RAMP (Results from Testing, Figures S7-S10)
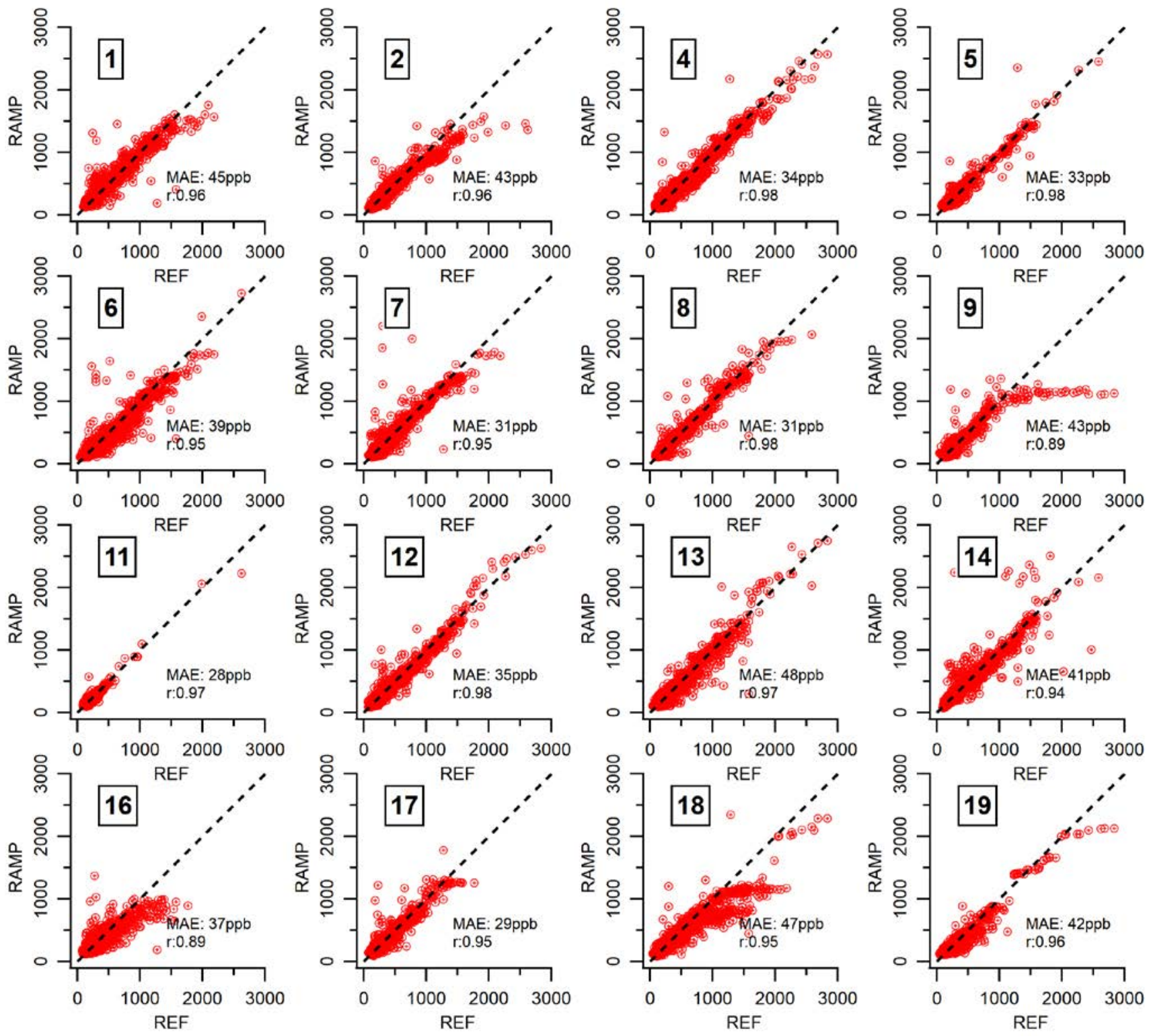

$\mathrm{CO}(\mathrm{ppb})$

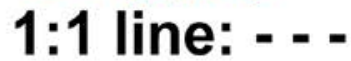

Figure S7: Model performance on testing data across 16 RAMPs for $\mathrm{CO}$ using random forests. 

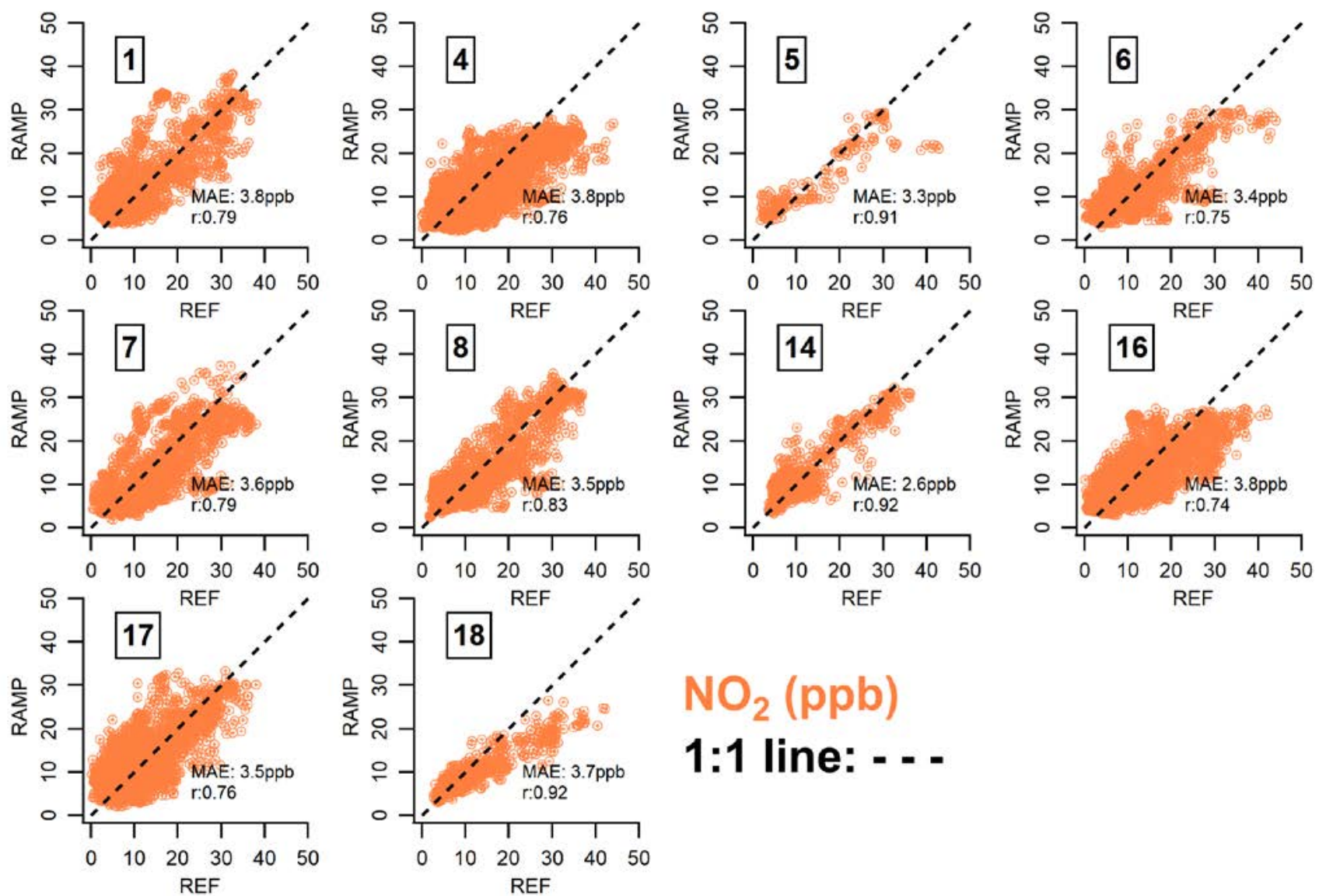

\section{$\mathrm{NO}_{2}$ (ppb)}

\section{1:1 line: - . -}

Figure S8: Model performance on testing data across 10 RAMPs for $\mathrm{NO}_{2}$ using random forests. 

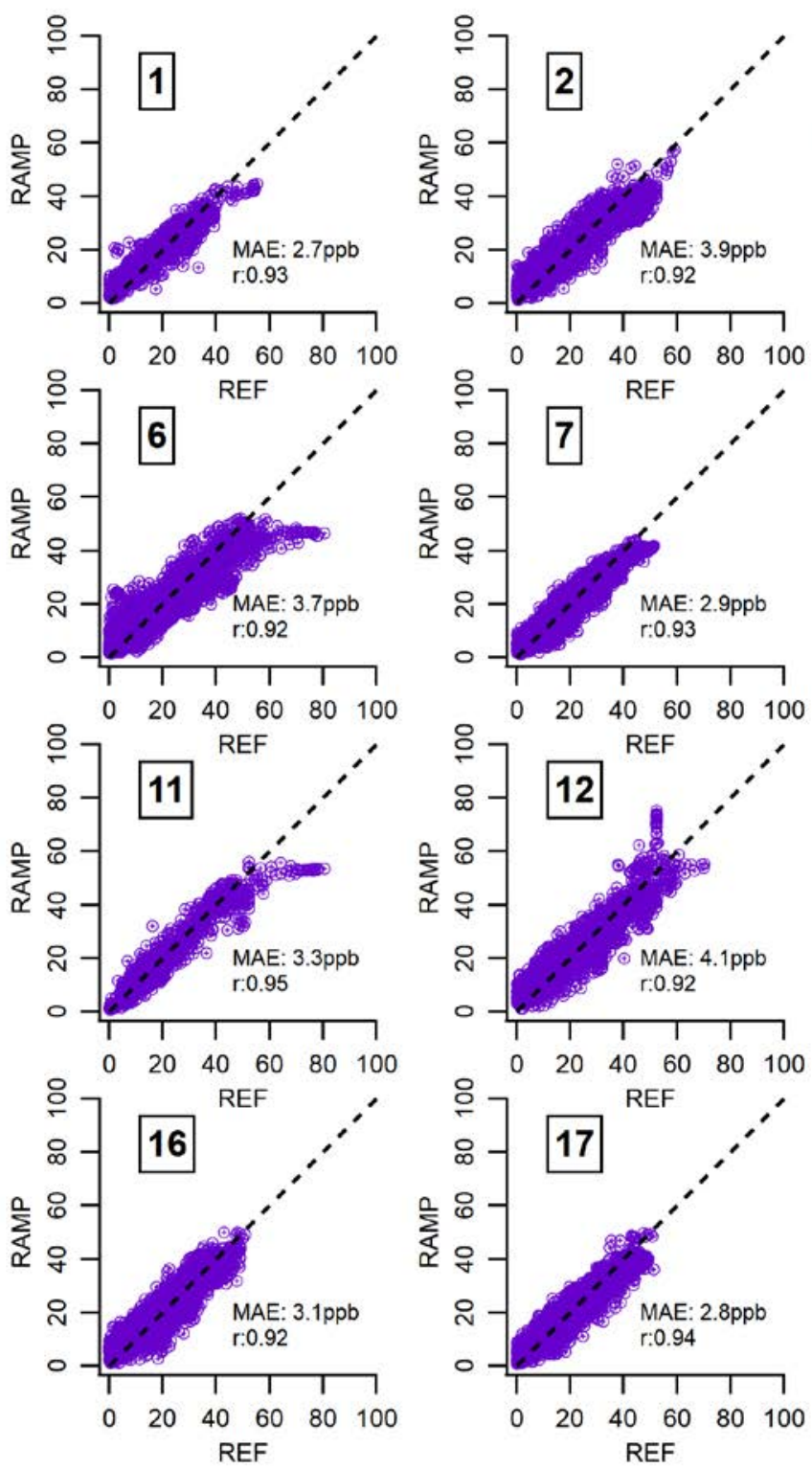
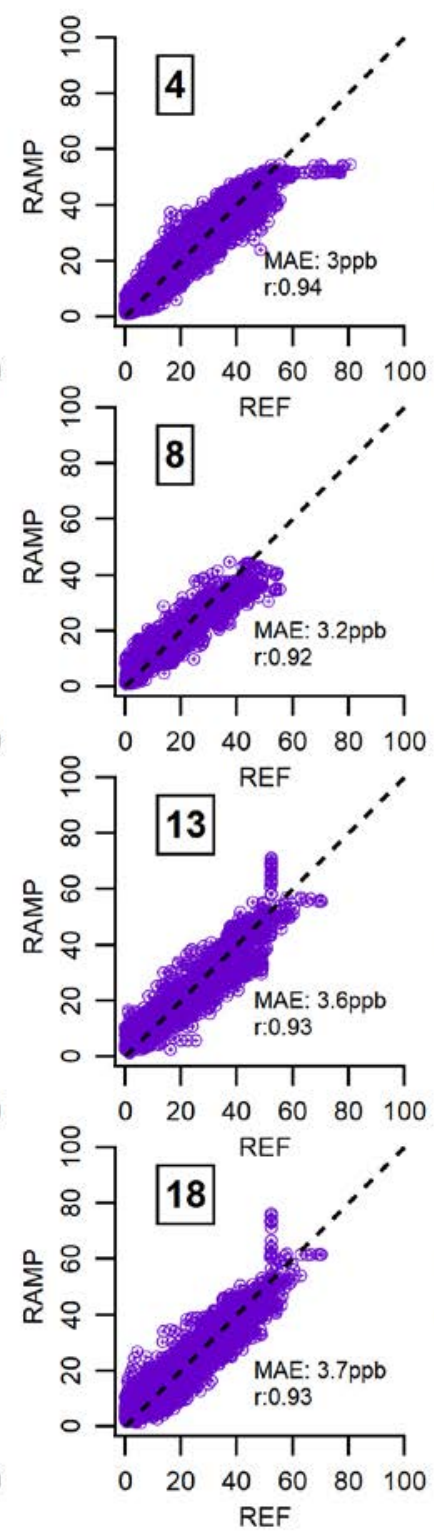
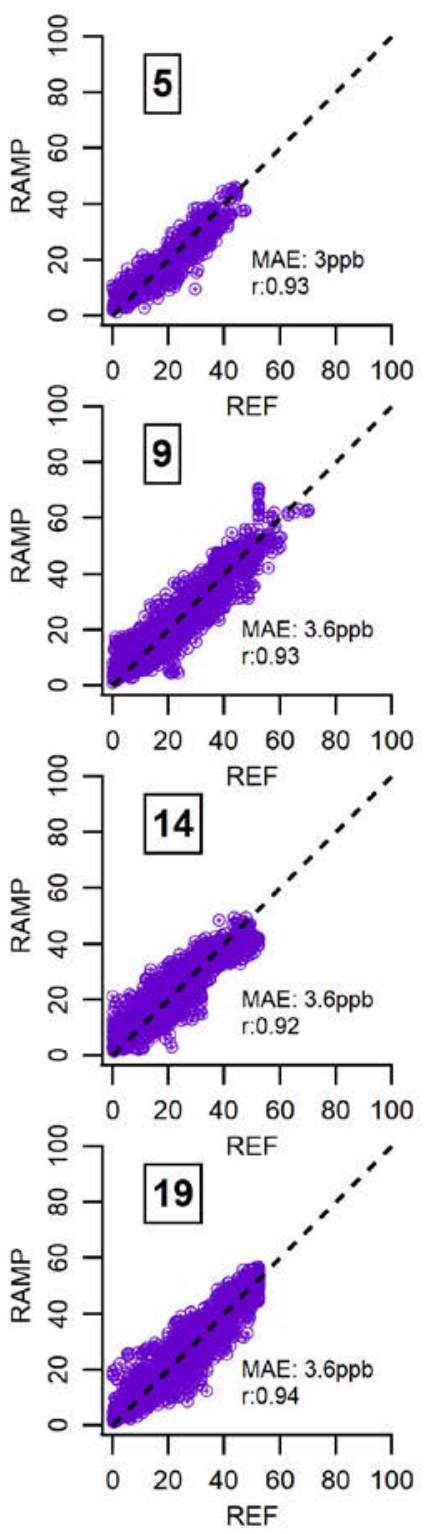

\section{$\mathrm{O}_{3}$ (ppb)}

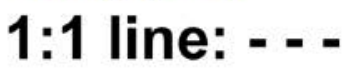

Figure S9: Model performance on testing data across 16 RAMPs for $\mathrm{O}_{3}$ using random forests. 

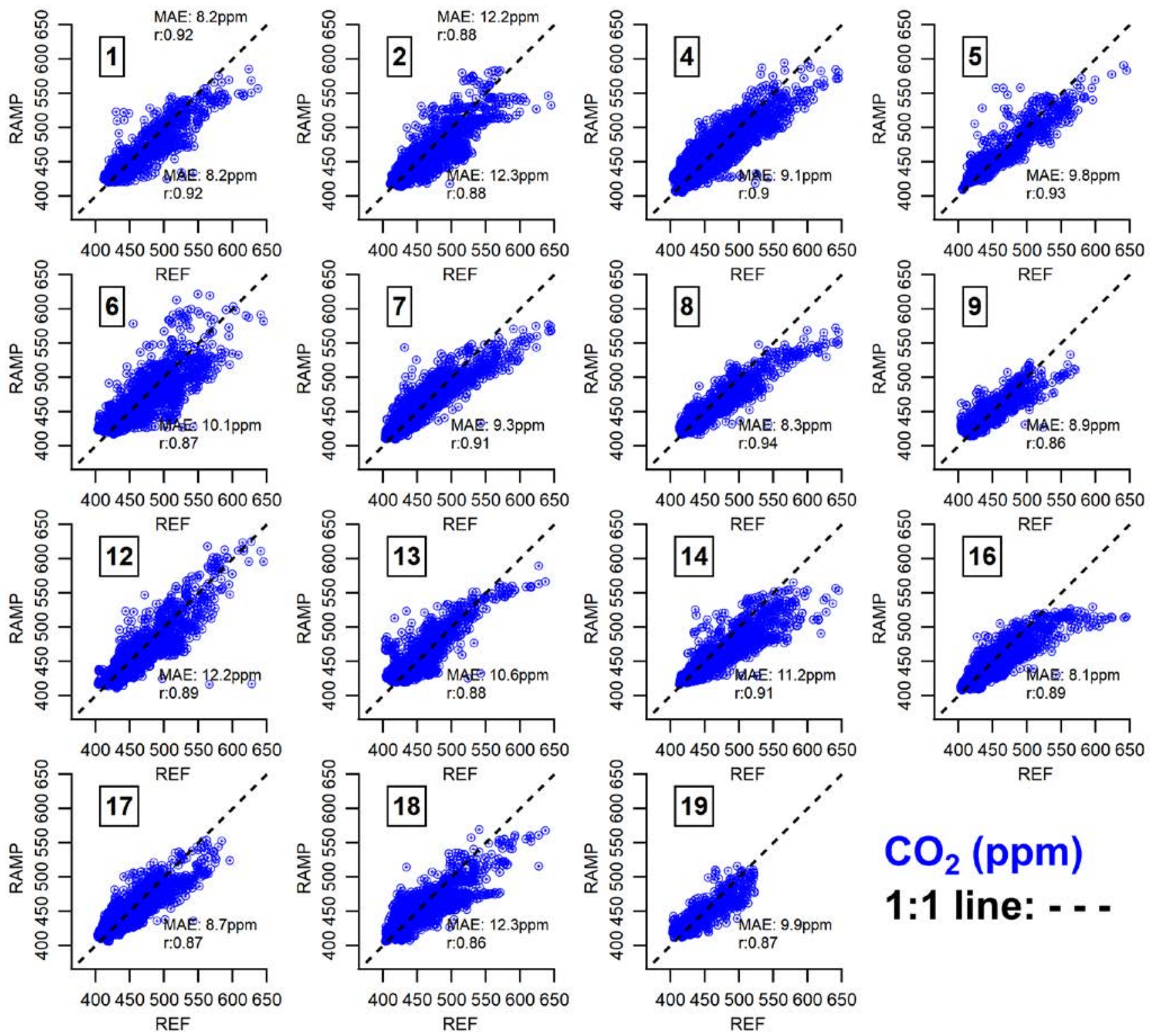

Figure S10: Model performance on testing data across 15 RAMPs for $\mathrm{CO}_{2}$ using random forests. 


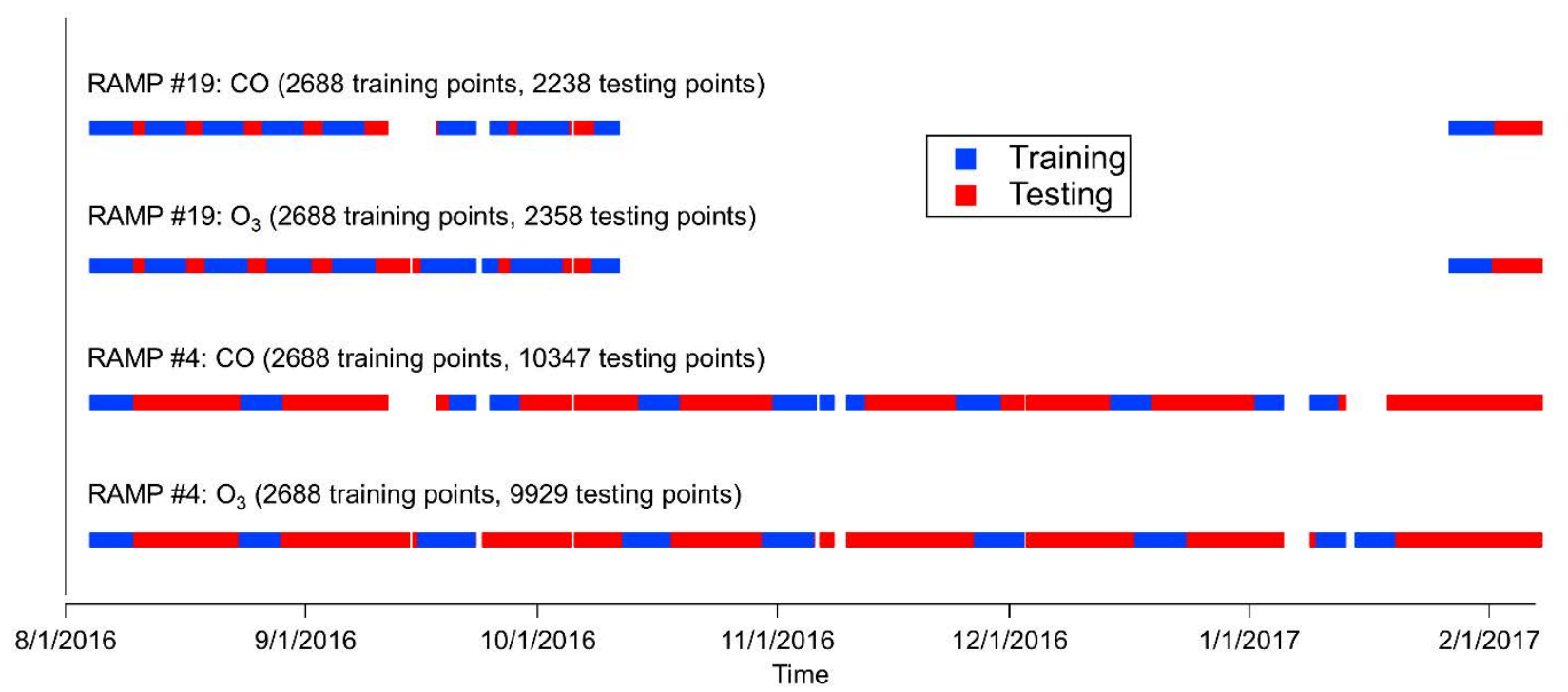

Figure S11: Examples of training and testing periods for two RAMPs. The training window (4 weeks) is the same for each sensor; remaining data are used for model testing. RAMP \#4 had the longest testing window (15 weeks), while RAMP \#19 had one of the shorter testing windows (under 4 weeks.) Only two sensors from each RAMP are shown for clarity. 


\section{US EPA Air Sensor Guidebook Precision and Bias Estimators:}

\section{Precision:}

The precision estimator (CV) is the upper bound of the $90 \%$ confidence interval on the coefficient of variation.

$$
\mathbf{C V}=\sqrt{\frac{n \cdot \sum_{i=1}^{n} d_{i}^{2}-\left(\sum_{i=1}^{n} d_{i}\right)^{2}}{n(n-1)} \cdot \sqrt{\frac{n-1}{\chi_{(0.1, n-1)}^{2}}}}
$$

Where $\mathrm{n}$ is the number of data points, $\chi_{(0.1, n-1)}^{2}$ is the $10^{\text {th }}$ percentile of a chi-squared distribution with n- 1 degrees of freedom, and $\mathrm{d}_{\mathrm{i}}$ is equal to:

$$
\mathbf{d}_{\mathbf{i}}=\frac{\text { RAMP }- \text { reference }}{\text { reference }} \cdot \mathbf{1 0 0} \%
$$

\section{Bias:}

The bias estimator is the upper bound of the $95 \%$ confidence interval on the mean absolute value of the percent difference between the RAMPs and the reference monitor.

$$
\mid \text { Bias } \mid=A B+t_{0.95, n-1} \cdot \frac{A S}{\sqrt{n}}
$$

Where $t_{0.95, n-1}$ is the $95^{\text {th }}$ quartile of a t-distibution with $n-1$ degrees of freedom and $A B$ is the mean of the absolute values of the $d_{i}$ 's.

$$
A B=\frac{1}{n} \sum_{i=1}^{n}\left|d_{i}\right|
$$

And AS is the standard deviation of the absolute value of the $d_{i}$ 's:

$$
\mathbf{A S}=\sqrt{\frac{\mathbf{n} \cdot \sum_{\mathrm{i}=1}^{\mathrm{n}}\left|\boldsymbol{d}_{i}\right|^{2}-\left(\sum_{\mathrm{i}=1}^{\mathrm{n}}\left|\boldsymbol{d}_{i}\right|\right)^{2}}{\mathbf{n}(\mathbf{n}-\mathbf{1})}}
$$

